\title{
51. Suggested Programming Projects
}

For each of the following projects - produce structure diagrams, a list of paragraph names to be used, a written version of the program before testing, a test plan and log, comments on any changes that were necessary to cure logic errors and a printout of the final correct version of the program.

1. An estate agent needs to be able to display (on the screen) a report on all properties under $£ 100,000$. Produce the following:

Program 1 - which will allow the user to key in details of properties and store them in a sequential file. Details should include:

$\begin{array}{lll}\text { address } & \text { alphanumeric } 100 \text { characters } \\ \text { number of rooms } & \text { numeric } & 2 \text { digits } \\ \text { name of vendor } & \text { alphanumeric } & 20 \text { characters } \\ \text { price } & \text { numeric } & 6 \text { digits }\end{array}$

Program 2 - which will read the file created by Program 1 and display a report showing details of all properties under $£ 100,000$.

2. A school needs to be able to keep records of students marks and be able to produce a list of pupils who are to receive prizes. Produce the following:

Program 1 - which will allow the teacher to key in details about each student and store them on disk. Details should include:

$\begin{array}{lll}\text { name } & \text { alphanumeric } & 20 \text { characters } \\ \text { maths mark } & \text { numeric } & 3 \text { digits } \\ \text { English mark } & \text { numeric } & 3 \text { digits } \\ \text { physics mark } & \text { numeric } & 3 \text { digits } \\ \text { French mark } & \text { numeric } & 3 \text { digits }\end{array}$

Program 2 - which will read the file created by Program 1 and display a list of all students whose average mark is greater than 70 - with the overall heading 'Prizes to be awarded to: '

3. A bank needs to produce a list of all customers accounts that are overdrawn. Produce the following:

Program 1 - which will allow the user to key in details about each customer's account and store the informnation on disk. Details should include:

$\begin{array}{lll}\text { account number } & \text { numeric } & 9 \text { digits } \\ \text { name } & \text { alphanumeric } & 20 \text { characters } \\ \text { address } & \text { alphanumeric } & 100 \text { characters } \\ \text { account balance at beginning of day } & \text { numeric } & 9 \text { digits including pence } \\ \text { (Remember that this } \text { item could be positive or negative) } & \\ \text { credit item } & \text { numeric } & 6 \text { digits including pence } \\ \text { debit item } & \text { numeric } & 6 \text { digits including pence }\end{array}$

Program 2 - which will read the file created by Program 1 and display report showing all customers who are overdrawn by the end of the day - including the names, account numbers and amount overdrawn. 